\title{
Freezing Point Depression
}

National Cancer Institute

\section{Source}

National Cancer Institute. Freezing Point Depression. NCI Thesaurus. Code C135453.

The addition of a solute to a solvent that results in a decrease in the temperature at which the solute-solvent mixture freezes. 